\title{
PENGARUH MOTIVASI KERJA DAN KOMUNIKASI EFEKTIF BUDAYA ORGANISASI TERHADAP KINERJA KARYAWAN PADA HOTEL RANGKAYO BASA
}

\section{EFFECT OF WORK MOTIVATION AND EFFECTIVE COMMUNICATION OF ORGANIZATIONAL CULTURE ON EMPLOYEE PERFORMANCE AT RANGKAYO BASA HOTEL}

\author{
Zike Martha ${ }^{1}$ Indria Flowerina ${ }^{2}$ Asni Dewi ${ }^{3}$ \\ ${ }^{1,2,3)}$ Universitas Dharma Andalas, Prodi Ilmu Komunikasi \\ zikemartha17@gmail.com, indriaflowerina17@gmail.com, asnidewi11@gmail.com
}

\begin{abstract}
ABSTRAK: Penelitian ini bertujuan untuk mengetahui Pengaruh Motivasi Kerja dan Komunikasi Efekti Budaya Organisasi terhadap Kinerja Karyawan pada Hotel Rangkayo Basa secara parsial dan simultan. Objek penelitian yang digunakan adalah Hotel Rangkayo Basa. Penelitian ini menggunakan teknik Total Sampling yaitu semua anggota populasi dijadikan sampel. Penelitian ini termasuk dalam jenis penelitian deskriptif kuantitatif. Metode analisis data yang digunakan dalam penelitian ini adalah analisis regresi linear berganda. Secara Parsial hasil pengujian hipotesis motivasi kerja menunjukkan nilai $\mathrm{t}$ hitung > t tabel dengan taraf signifikansi 0,20, berarti motivasi kerja berpengaruh signifikan terhadap kinerja karyawan Hotel Rangkayo Basa.

Kata Kunci: Motivasi Kerja, Komunikasi Efektif, Budaya Organisasi, Kinerja Karyawan

ABSTRACT: This study aims to see the effect of work influence and communication on the effectiveness of organizational culture on employee performance at the Rangkayo Basa hotel partially and simultaneously. The research object used was the Rangkayo Basa Hotel. The research used total sampling technique, in which all members of the population were sampled. This research is included in the type of quantitative descriptive research. The data analysis method used in this study is multiple linear regression analysis. Partially the results of testing the motivation hypothesis show the value of $t$ count $>t$ table with a significance value of 0.20 , meaning that work motivation has a significant effect on the employee performance of the Rangkayo Basa Hotel.
\end{abstract}

Keywords: Work Motivation, Effective Communication, Organizational Culture, Employee Performance

\section{A. PENDAHULUAN}

Dalam melakukan kegiatan operasional, tersedianya sumber daya modal dan teknologi belum merupakan suatu jaminan tercapainya tujuan suatu organisasi, sebab masih ada faktor lain yang begitu besar perananya yaitu Sumber daya manusia. Sumber Daya Manusia sebagai penggerak organisasi dalam mencapai tujuannya, maka upaya-upaya organisasi dalam mendorong karyawan untuk bekerja lebih baik harus terus dilakukan, dengan adanya karyawan-karyawan yang bekerja secara baik ini, maka di harapkan kinerja karyawan yang baik juga tercapai oleh karyawan dalam melaksanakan tugasnya sesuai dengan tanggung jawab yang diberikan kepadanya. Tercapainya tujuan organisasi tidak hanya tergantung pada peralatan modern, sarana dan prasarana yang lengkap, tetapi justru lebih tergantung pada manusia yang melaksanakan pekerjaan tersebut. 
Keberhasilan suatu organisasi sangat dipengaruhi oleh komunikasi efektif budaya organisasi terhadap kinerja karyawan.

Berdasarkan latar belakang dan permasalahan diatas, maka tujuan dari penelitian ini sebagai berikut :

Untuk mengetahui pengaruh Motivasi Kerja terhadap Kinerja Karyawan pada Hotel Rangkayo Basa.

Untuk mengetahui pengaruh Komunikasi Efektif Budaya Organisasi terhadap Kinerja Karyawan pada Hotel Rangkayo Basa.

Untuk mengetahui pengaruh Motivasi Kerja dan Komunikasi Efektif Budaya Organisasi secara simultan terhadap Kinerja Karyawan pada Hotel Rangkayo Basa.

Kinerja merupakan hasil pekerjaan yang mempunyai hubungan kuat dengan tujuan strategis organisasi, kepuasan konsumen dan memberikan kontribusi pada ekonomi (Wibowo, 2013). Menurut Hasibuan (2010) kinerja merupakan perwujudan kerja yang dilakukan oleh karyawan yang biasanya dipakai sebagai dasar penilaian terhadap karyawan atau organisasi. Kinerja atau dalam bahasa inggris adalah performance, yaitu hasil kerja yang dapat dicapai oleh seseorang atau sekelompok orang dalam organisasi, sesuai dengan wewenang dan tanggung jawab masingmasing dalam rangka upaya mencapai tujuan organisasi bersangkutan secara legal, tidak melanggar hukum dan sesuai dengan moral maupun etika (Prawirosentono, 2013). Kinerja pada umumnya dikatakan sebagai ukuran bagi seseorang dalam pekerjaannya. Kinerja dari setiap pekerja harus mempunyai nilai tambah bagi suatu organisasi atas penggunaan sumber daya yang telah dikeluarkan.

Penilaian kinerja penting dilakukan untuk mengukur dan mengevaluasikinerja karyawan walaupun sering kali dianggap negatif bagikaryawan. padahal penilaian kinerja bermanfaat baik bagi perusahaanmaupun karyawan. Proses penilaian kinerja menurut Mondy(2010), yaitu:

Mengidentifikasi tujuan-tujuan penilaian spesifik

Menetapkan kriteria-kriteria kinerja dan mengkomunikasikannya kepada karyawan

Memeriksa pekerjaan yang dijalankan

Menilai kinerja

Mendiskusikan penilaian bersama karyawan

Untuk mengetahui kinerja karyawan diperlukan kegiatan-kegiatan khusus. Sutrisno (2013) mengajukan 6 (enam) kinerja primer yang dapat digunakan untuk mengukur kinerja, yaitu:

$$
\text { Quality (Kualitas) }
$$

Kualitas merupakan tingkat sejauh mana proses atau hasil pelaksanaan kegiatan mendekati kesempurnaan atau mendekati tujuan yang diharapkan.

\section{Quantity (kuantitas)}

Kuantitas merupakan jumlah yang dihasilkan, misalnya jumlah rupiah, unit, atau siklus kegiatan yang dilakukan.

Timeliness (ketepatan waktu) 
Ketepatan waktu merupakan sejauh mana suatu kegiatan diselesaikan pada waktu yang dikehendaki, dengan memerhatikan koordinasi output yang lain serta waktu yang tersedia untuk kegiatan orang lain.

\section{Cost Efectiveness (efektivitas biaya)}

Eektivitas biaya merupakan tngkat sejauh mana penggunaan sumber daya organisasi (manusia, keuangan, teknologi, dan material) dimaksimalkan untuk mencapai hasil tertinggi atau pengurangan kerugian dari setiap unit penggunaan sumber daya.

\section{Need for supervision (keperluan pengawasan)}

Keperluan pengawasan merupakan tingkat sejjauh mana seseorang pekerja dapat melaksanakan suatu fungsi pekerjaan tanpa memerlukan pengawasan seorang supervisor untuk mencegah tindakan yang kurang diinginkan.

\section{Interpersonal Impact (dampak interpersonal)}

Dampak interpersonal merupakan tingkat sejauh mana karyawan memelihara harga diri, nama baik, dan kerja sama di antara rekan kerja dan bawahan. Penilaian kinerja karyawan perlu dilakukan agar perusahaan dapat mengevaluasi sebatas mana kinerja yang telah dilakukan karyawan terhadap perusahaan. Penilaian ini dilakukan dengan mengidentifikasi tujuan penilaian tersebut secara spesifik. Selanjutnya, atasan memeriksa pekerjaan yang sedang dijalankan karyawan lalu menilai kinerjanya. Setelah penilaian tersebut dilakukan, hasil penilaian tersebut didiskusikan dengan karyawan untuk menemukan solusi dalam mengatasi kinerja yang buruk.

\section{Relevansi dan kemuktakiran Pengaruh Motivasi Kerja terhadap Kinerja Karyawan}

Relavasi dan kemuktakiran motivasi adalah kondisi yang berpengaruh membangkitkan, mengarahkan dan memelihara perilaku yang berhubungan dengan lingkungan kerja selain itu mendukung penelitian dahulu serta memberikan penelitian yang akan datang untuk penelitian selanjutnya.

Menurut Pranoto (2014), motivasi kerja terbukti mempunyai suatu pengaruh positif dan signifikan terhadap kinerja karyawan dan menurut Saputra (2015), Adanya hubungan yang positif dan signifikan antara variabel motivasi terhadap kinerja Karyawan hotel Plaza Semarang.Pengaruhyang ditimbulkan menunjukkan hubungan yang positif dengan kinerja, artinyamotivasi yang ada dalam diri karyawan maupun yang berasal dari luar lingkungandapat membantu dalam meningkatkan kinerja.Berdasarkan uraian tersebut, maka hipotesis penelitian adalah :

\section{H1: Diduga Motivasi Kerja berpengaruh signifikan terhadap Kinerja Karyawan pada Hotel Rangkayo Basa \\ Pengaruh Komunikasi efektif budaya organisasi terhadap Kinerja Karyawan}

Komunikasi efektif budaya organisasi adalah perangkat sistem nilai-nilai (values), keyakinankeyakinan (beliefs), asumsi-asumsi (assumptions), atau norma-norma yang telah berlaku lama, disepakati dan diikuti oleh anggota suatu organisasi sebagai pedoman perilaku dan pemecahan masalah-masalah organisasinya (Sutrisno,2010). Komunikasi efektif budaya organisasi didalam sebuah perusahaan adalah sarana untuk mempersatukan antar individu yang memiliki karakter dan sifat yang berbeda-beda sehingga individu dapat menjalankan dan melaksanakan kegiatan secara 
bersama-sama yang sesuai dengan prosedur dan aturan yang telah ditetapkan oleh perusahaan atau organisasi.

Menurut Subagiyono (2015), ada pengaruh signifikan secara parsial antara variabel komunikasi efektif budaya organisasi terhadap variabel terikat kinerja karyawan. Hal ini mengindikasikan komunikasi efektif budaya organisasi mampu memberikan pengaruh pada peningkatan kinerja karyawan. Dan Menurut Saputra (2015), Adanya hubungan yang positif dan signifikan antara variabel komunikasi efektif budaya organisasi terhadap kinerja Karyawan hotel Plaza Semarang. Hal ini menunjukkan bahwa komunikasi efektif budaya organisasi perusahaan telah diterima dandipahami dengan baik oleh karyawanBerdasarkan uraian tersebut, maka hipotesis penelitian adalah :

H2: Diduga Komunikasi efektif budaya organisasi berpengaruh signifikan terhadap Kinerja Karyawan pada Hotel Rangkayo Basa Pengaruh Motivasi Kerja dan Komunikasi efektif budaya organisasi terhadap Kinerja Karyawan

Menurut Pranoto (2014), komunikasi efektif budaya organisasi dan motivasi kerja, ternyata terbukti berpengaruh secara signifikan terhadap kinerja karyawan dan Saputra (2015), Komunikasi efektif budaya organisasi dan motivasi secara simultan mempunyai pengaruh yang signifikan terhadap kinerja karyawan. Komunikasi efektif budaya organisasi dan motivasi juga dapat dikatakan salah satu cara dalammencapai tujuan organisasi, dimana pelaksanaannya disesuaikan dengan kesiapankaryawan menerima komunikasi efektif budaya organisasi dan motivasi tersebut. Pihak manajemendalam mendukung komunikasi efektif budaya organisasi dan motivasi juga perlu memperhatikandan meningkatkan kualitas dari potensi kinerja karyawan misalnya denganpemberian kesempatan melanjutkan mengikuti pendidikan bagi yang berminat danmengikutsertakan dalam berbagai pelatihan. Berdasarkan uraian tersebut, maka hipotesis penelitian adalah :

\section{H3: DidugaMotivasi Kerja dan Komunikasi efektif budaya organisasi berpengaruh signifikan terhadap Kinerja Karyawan pada Hotel Rangkayo Basa}

\section{B. METODE PENELITIAN}

Pada prinsipnya pengujian hipotesis ini adalah membuat kesimpulan sementara untuk melakukan penyanggahan atau pembenaran dari masalah yang akan ditelaah. Sebagai wahana untuk menetapkan kesimpulan sementara tersebut kemudian ditetapkan hipotesis nol dan hipotesis alternatifnya. Langkah-langkah dalam analisisnya adalah sebagai berikut:

\section{Uji T (Uji Hipotesis Secara Parsial)}

Hipotesis dalam penelitian ini diuji kebenarannya dengan menggunakan uji parsial. Pengujian dilakukan dengan melihat taraf signifikansi (pvalue), jika taraf signifikansi yang dihasilkan dari perhitungan di bawah 0,05 maka hipotesis diterima, sebaliknya jika taraf signifikansi hasil hitung lebih besar dari 0,05 maka hipotesis ditolak.

Perumusan hipotesis:

Ho: tidak ada pengaruh positif dan signifikan antara motivasi kerja dan budaya organisasi terhadap kinerja karyawan.

Ha: ada pengaruh positif dan signifikan antara motivasi kerja dan budaya organisasi terhadap kinerja karyawan. 


\section{HASIL DAN PEMBAHASAN}

\section{Pengaruh Motivasi Kerja terhadap Kinerja Karyawan}

Hasil pengujian hipotesis motivasi kerja menunjukkan nilai $t$ hitung 2,442 > t tabel 2,032 dengan taraf signifikansi 0,20 . Taraf signifikansi tersebut lebih kecil dari 0,05 , yang berarti bahwa hipotesis dalam penelitian ini menolak Ho dan menerima Ha.

\section{Pengaruh Budaya Organisasi terhadap Kinerja Karyawan}

Hasil pengujian hipotesis budaya organisasi menunjukkan nilai t hitung 2,205 > t tabel 2,032 dengan taraf signifikansi 0,035 . Taraf signifikansi tersebut lebih kecil dari 0,05 , yang berarti bahwa hipotesis dalam penelitian ini menolak Ho dan menerima Ha. Dengan demikian dapat berarti bahwa hipotesis $\mathrm{H} 2$ "budaya organisasi berpengaruh signifikanterhadapkinerja karyawan Hotel Rangkayo Basa".

\section{Pengaruh Motivasi Kerja dan Budaya Organisasi terhadap Kinerja Karyawan}

Hasilpengujian hipotesis motivasi kerja dan budaya organisasi menunjukkan nilai f hitung 10,388 $>\mathrm{F}$ tabel 3,28 dengan taraf signifikansi 0,000. Tarafsignifikansi tersebut lebih kecil dari 0,05, yang berarti bahwa hipotesis dalam penelitian ini menolak Ho dan menerima Ha. Dengan demikian dapat berarti bahwa hipotesis H3"motivasi kerja dan budaya organisasi mempunyai pengaruh signifikan terhadap kinerja karyawan Hotel Rangkayo Basa”.

\section{KESIMPULAN}

Tarafsignifikansi tersebut lebih kecil dari 0,05, yang berarti bahwa hipotesis dalam penelitian ini menolak Ho dan menerima Ha. Dengan demikian dapat berarti bahwa hipotesis H3 "motivasi kerja dan budaya organisasi mempunyai pengaruh signifikan terhadap kinerja karyawan Hotel Rangkayo Basa". Besar pengaruh motivasi kerja dan budaya organisasi terhadapkinerja karyawan adalahsebesar 0,349 atau $34,9 \%$ sedangkan sisanya $65,1 \%$ dipengaruhi oleh faktor lainnya seperti gaji, kompetensi, dll.

\section{SARAN}

Berdasarkan perumusan masalah dan telah dibahas pada bab sebelumnya maka peneliti menyarankan sebagai berikut:

1. Berdasarkan hasil uji hipotesi variabel Motivasi Kerja berpengaruh terhadap kinerja karyawan, maka penelitia menyarankan agar dapat Apabila perusahaan memberikan tugas baru diluar tugas rutin, sebaiknya diiringi dengan pemberian reward.

2. Berdasarkan hasil uji hipotesi variabel Motivasi Kerja berpengaruh terhadap kinerja karyawan, maka penelitian menyarankan agar dapat perusahaan lebih diperbayak lagi kriteria-kriteria dalam pemberian reward supaya semakin semangat dalam bekerja tanpa menunggu perintah pimpinan.

3. Berdasarkan hasil uji hipotesi variabel Budaya Organisasi berpengaruh terhadap kinerja karyawan, maka penelitian menyarankan agar dapat Sebaiknya karyawan diberikan pelatihan, sosialisasi, liburan antar karyawan supaya mempeerat hubungan kerjasama karyawan.

4. Berdasarkan hasil uji hipotesi variabel Kinerja Karyawan, maka penelitian menyarankan agar dapat Memberikan pelatihan kepada karyawan bermanfaat untuk menambah pengetahuan mereka mengenai hal yang berhubungan dengan pekerjaan, apalagi ada pemberian tugas tambahan. 


\section{E. DAFTAR PUSTAKA}

Agus, Lutfi, dkk. 2016. Pengaruh Budaya Organisasi dan Motivasi Terhadap Kinerja Karyawan (Perawat) Pada Rumah Sakit Wijaya Kusuma Kabupaten Lumajang. Universitas Jember. Jurnal Ekonomi dan Bisnis. Vol.7 No.10.https://scholar.google.co.id/

Armiaty, Rina dan Zakhyadi Ariffin. 2014. Pengaruh Budaya Organisasi Dan Motivasi Terhadap Kinerja Pegawai Frontliner (Studi Pada Cabang Bank Kalsel Yang Berada Di Wilayah Banjarmasin). Universitas Lambung Mangkurat. Jurnal Wawasan Manajemen. Vol.2 No.2. http://jwm.ulm.ac.id/

Deddy Mulyana. 2014. Metode Penelitian Kuantitatif, Kualitatif, dan R\&D. Bandung: Penerbit Alfabeta.

Ghozali, Imam. 2013. Amplikasi Analisis Multivariate dengan Program SPSS. Edisi Ketujuh. Semarang: Badan Penerbit Universitas Diponegoro.

Gijoh, Rienly. 2013. Motivasi, Kompetensi dan Budaya Kerja Pengaruhnya terhadap Kepuasan Kerja Karyawan Outsourcing pada Hotel Sintesa Peninsula Manado. Universitas Sam Ratulangi. Jurnal EMBA. Vol.1 No.4. https://ejournal.unsrat.ac.id/

Gomes, Faustino Cardoso. 2013. Manajemen Sumber Daya Manusia. Yogyakarta: Andi. Gujarati, Damodar N. 2015. Dasar-Dasar Ekonometrika. Buku II. Edisi Kelima. JakartaSelatan: Salemba Empat.

Hasibuan, Malayu S.P. 2010. Manajemen Sumber Daya Manusia. Jakarta: PT Bumi Aksara. Kurniawan, Albert. 2014. Metode Riset untuk Ekonomi dan Bisnis: Teori, Konsep, dan Praktik Penelitian Bisnis (Dilengkapi Perhitungan Pengolahan Data dengan IBM SPSS 22.0). Bandung: Alfabeta.

Mangkunegara, Anwar Prabu. 2014. Manajemen Sumber Daya Manusia Perusahaan..Bandung: PT. Remaja Rosdakarya.

Mathis, Robert L. dan John H. Jackson. 2012. Manajemen Sumber Daya Manusia, Edisi Pertama Jakarta: Salemba Empat.

Mondy. 2010. Manajemen Sumber Daya Manusia. Jakarta: Salemba Empat.

Nadhira Siti Rahma dan Anthon Rustono. 2018. Pengaruh Budaya Organisasi Dan Motivasi Terhadap `Kinerja Karyawan (Studi Kasus Pada PT Telekomunikasi Indonesia Witel Jakarta Selatan Unit Hr\&Cdc Dan Network Area). Universitas Telkom. Vol.5 No.1. https://scholar.google.co.id/

Pranoto, Paulus Sugiyo. Pengaruh Budaya Organisasi Dan Motivasi Kerja Terhadap Kinerja Karyawan PT Crea Cipta Cemerlang Surabaya. Jurnal Ilmu Manajemen. Vol.2 No.4. https://ejournal.unja.ac.id/

Prawirosentono, Suyadi. 2013. MSDM Kebijakan Kinerja Karyawan. Yogyakarta: BPFE. Rivai, Veithzal. 2011, Manajemen Sumber Daya Manusia untuk Perusahaan: dari Teori kePraktik, Jakarta: RajaGrafindo Persada.

Robbins, P.Stephen dan Timothy A. Judge. 2012. Perilaku Organisasi. Jakarta: Salemba Empat.

Robbins, Stephen P \& Judge, Timothy A. 2013. Organizational Behavior Edition 15. New Jersey: Pearson Education. 
Saputra, Dhany Bagus dan Indi Djastuti. 2015. Pengaruh Budaya Organisasi dan Motivasi terhadap Kinerja Karyawan Hotel Plaza Semarang. Universitas Dipenogoro. Vol. 4 No.

1.https://scholar.google.co.id/

Warsito, Bambang. 2018. Pengaruh Budaya Organisasi dan Lingkungan Kerja terhadap Organizational

Citizenship Behavior, Motivasi dan Kinerja pada Hotel Berbintang di Kota Malang dan Batu. Universitas Kanjuruhan. Jurnal Ekonomi. Vol. 4 No. 2. https://scholar.google.co.id/

Wibowo. 2013. Manajemen Kinerja. Jakarta: Rajawali Pers. 